\title{
Pengaruh Sri Sultan Hamengku Buwono I pada Seni Karawitan Kraton Yogyakarta
}

\author{
Raharja ${ }^{1}$ \\ Jurusan Karawitan, Fakultas Seni Pertunjukan, Institut Seni Indonesia Yogyakarta \\ Timbul Haryono, R.M. Soedarsono, dan Adhi Susanto \\ Pengkajian Seni Pertunjukan dan Seni Rupa, Universitas Gadjah Mada Yogyakarta
}

\begin{abstract}
ABSTRAK
Gamelan sebagai alat musik atau karawitan sebagai produk musikal dari Kraton Yogyakarta mempunyai beberapa karakter yang sangat khas. Karawitan masih dipergunakan sebagai suatu identitas dan diakui oleh masyarakat hingga saat ini. Pengembangan musikal ini bermula dari Sri Sultan Hamengku Buwono I. Ada dua alasan penting yang mendorong gagasan penciptaan karakter gamelan. Pertama, konsepsi kedudukan raja telah mendudukkan gamelan sebagai salah satu pusaka penting. Kedua, kepribadian Sultan yang maskulin, heroik, dan patriotik menjadi model pengembangan, memberi ciri khas pada masing-masing ricikan gamelan dan musikalitasnya. Gamelan Kraton Yogyakarta mempunyai kesan rasa musikal: agung, gagah, tegas, mantap, berwibawa, mrabu (seperti raja), dan ngratoni (seperti suasana di kraton).
\end{abstract}

Kata kunci: Sri Sultan Hamengku Buwono I, Kraton Yogyakarta, karakter gamelan, konsepsi kedudukan raja, kepribadian, maskulinitas, heroisme, patriotisme

\begin{abstract}
The Effect of Sri Sultan Hamengku Buwono I on Kraton Yogyakarta Karawitan. Gamelan as musical instrument or karawitan as a musical product of Kraton Yogyakarta has some specific characters. It is still used as an identity and is recognized by karawitan society until now. This musical development was firstly introduced by Sri Sultan Hamengku Buwono I. There are two important reasons which stimulate the ideas of creating gamelan characters. First, the king's authority conception puts the gamelan as one of the important heirloom. Second, Sultan's personalities which are masculine, heroic, and patriotic become the influencing model of its development, and give some specific characters on each gamelan instrument and its musicality as well. Kraton Yogyakarta gamelan has many musical rasa(s)/feelings: glorious, strong, clear, steady, prestigious, 'mrabu' (like a king), and 'ngratoni' (such an atmosphere of Kraton).
\end{abstract}

Keywords: Sri Sultan Hamengku Buwono I, Kraton Yogyakarta, gamelan character, king's authority conception, personality, masculinity, heroism, patriotism

\section{Pendahuluan}

Sri Sultan HB I (1755-1792) adalah putera Sunan Amangkurat IV (1719-1726). Ia lahir pada malem Rebo Pon (malam Rabu Pon) tanggal 26 Ruwah taun Wawu 1641, Mangsa Kalima, Wuku Tolu, Windu Sancaya atau tanggal 4 Agustus 1717 Masehi (Djoko Dwiyanto \& Purwadi, 2002: 1). Ia dinobatkan menjadi raja di Yogyakarta pada tanggal 11 Oktober 1755 dengan nama dan gelar Sri Sultan
Hamengku Buwono I. Kedudukan tersebut resmi diberikan pada Perjanjian Giyanti (13 Februari 1755) (Soedarsono, 2003: 101-102). Secara lengkap, gelarnya adalah 'Ngarsa Dalem Sampeyan Dalem Ingkang Sinuwun Kanjeng Sultan Hamengku Buwana Senapati Ing Ngalaga Khalifatullah Ngabdulrahman Sayidin Panatagama Ingkang Jumeneng Ing Nagari Ngayogyakarta Hadiningrat Ingkang Jumeneng Kaping Sepisan' (Margana, 2010: 4-6). Selain itu, ada gelar tambahan lagi, yaitu:

\footnotetext{
Alamat korespondensi: : Jurusan Karawitan, Fakultas Seni Pertunjukan, Institut Seni Indonesia Yogyakarta. Jln. Parangtritis km 6,5, Sewon, Yogyakarta 55001. Tlp. (0274) 375 380. Email: mas_raharja@yahoo.com
} 


\section{'Ingkang Tuhu Mandhireng Ing Nuswa Jawa' (Yang} Benar-Benar Berkuasa di Pulau Jawa) (Soedarsono, 1997: 157-158). Ia memerintah selama kurang lebih tigapuluh tujuh tahun dan wafat pada jam 23.00, hari Minggu Kliwon, tanggal 1 Ruwah taun Je, tahun Jawa 1718 atau Sabtu malam tanggal 24 Maret 1792 Masehi (Djoko Dwiyanto \& Purwadi, 2002: 29).

Seorang raja memiliki peran khusus dalam kehidupannya dan harus selalu menjaganya supaya selalu dalam keadaan seimbang dan harmonis. Peran yang dimaksud mempunyai tujuan agar legitimasinya sebagai penguasa tidak hilang (Nurhayati, 2006: 68-69). Jadi, untuk mendapatkan kondisi tersebut harus memahami dengan baik hubungan antara mikrokosmos dan makrokosmos (Nurhayati, 2006: 64). Heine-Geldern mengatakan, bahwa negara-negara di Asia Tenggara didirikan atas konsepsi keagamaan dan filisofis. Kerajaan dan jagat raya akan menjadi harmonis bila kerajaan dapat dikelola sebagai gambaran kecil dari jagat raya. Jadi, salah satu tugas raja adalah menjaga keteraturan atau keseimbangan antara kerajaan yang dipimpinnya dengan jagat raya (Soedarsono, 1997: 118). Sri Sultan HB I mempunyai wilayah kekuasaan sangat luas. Awal masa perkembangan Kraton Yogyakarta banyak menghadapi permasalahan. Contohnya adalah peristiwa kraman atau upaya perebutan kekuasaan yang terjadi di beberapa wilayah. Oleh sebab itu, untuk mengantisipasi meluasnya kejadian serupa, maka Sultan merancang suatu konsepsi kedudukan agar dapat menjaga legitimasinya sebagai raja. Adapun cara yang dilakukan, yaitu melalui beberapa aspek seperti berikut.

\section{Nama, Gelar, Wisnuisme, dan Silsilah}

Sejak Perjanjian Giyanti, Pangeran Mangkubumi mendapat hak untuk menentukan nama dan gelar kebangsawanannya. Gelar 'Sultan' dimaksudkan untuk menunjukkan ciri sebagai penguasa kerajaan yang religiusitasnya berlandaskan agama Islam (Soelarto, tt.: 38). 'Hamengku Buwono' ditujukan untuk mengidentifikasikan dirinya sebagai Dewa Wisnu (dewa pemelihara atau dengelola Dunia). Selain itu juga mengidentifikasikan diri sebagai Arjuna, salah satu pahlawan besar dalam wiracarita Mahabarata yang juga dianggap sebagai inkarnasi
Dewa Wisnu. Konsepsi seperti itu berakar dari budaya India, yaitu devaraja (Soedarsono, 1997: 127-130). Wisnuisme menjadi salah satu ciri dari kerajaan Mataram, meskipun agama Islam menjadi latar belakang sikap religiusitasnya (Soedarsono, 1997: 173). Brandon (2003: 21) mengatakan bahwa raja-raja di Kamboja dan Jawa mendewakan diri sebagai reinkarnasi dari salah satu dewa (Shiwa, Wisnu) atau Budha. Artinya, dengan cara tersebut Sultan mewarisi konsepsi ke-agungbinathara-an (raja besar yang didewakan) leluhurnya (Moedjanto, 2007: 81). Gelar yang panjang memuat beberapa kedudukan dan tugas dibalik statusnya sebagai raja. Selain itu, orang yang mempunyai gelar tersebut harus disembah dan dihormati karena sosok yang dimaksud mempunyai beberapa tugas mulia di dunia ini (Soelarto, tt.: 36). Menurut Moedjanto (1994: 86), silsilah Pangeran Mangkubumi adalah generasi kelimabelas dari raja Brawijaya $V$ atau kedelapan dari Panembahan Senopati (pendiri kerajaan Mataram Islam Kotagede). Selain itu, untuk menjaga kedudukannya dibuatkan silsilah panengen (keturunan dari pihak ibu) yang berujung pada keturunan wali atau Nabi Muhammad dan silsilah pangiwa (keturunan dari pihak bapak) yang berujung pada keturunan dewa atau Nabi Adam. Melalui konsepsi tersebut, masyarakat mengetahui bahwa rajanya adalah keturunan dari tokoh-tokoh yang kuat dan terkenal.

\section{Pusaka Keraton}

Semenjak Perjanjian Giyanti semua benda pusaka kerajaan Mataram dibagi menjadi dua (Waridi, 2006: 128). Banyaknya warisan pusaka yang diterima merupakan ukuran kebesaran, kewibawaan, dan kekuasaan raja (Vetter, 1986: 130). Kehidupan kraton Yogyakarta saat itu sama dengan zaman pra-Islam. Sultan menjalankan budaya dengan mengelola semua pusaka yang dimiliki. Ada dua jenis pusaka penting yang selalu dihadirkan dalam upacara di kraton. Pertama, adalah benda upacara milik kerajaan, yaitu: banyak, dhalang, sawung, galing, hardawalika, kutug, kacu mas, kandhil, saput, kecohan. Kelima pusaka pertama berbentuk binatang yang melambangkan bahwa raja tidak 
hanya menguasai manusia, tetapi juga berbagai jenis binatang. Seperti ungkapan dalam sastra pedalangan, yaitu: ambawahaken kutu-kutu walang ataga (menguasai semua jenis binatang). Kedua adalah benda upacara milik Sultan, yaitu: dhampar kencana, pancadan, dhampar cepuri, cepuri, kecohan, sangga kecohan, ginodhong, paturasan, wijikan, badhak, kendhaga, gandewa, endhong, tameng, golok, bedhil, dan pedang (Soelarto, tt.: 75-76).

Beberapa pusaka lainnya berupa tombak, keris, bendera, alat musik perang, peralatan memasak, dan baju warisan dari Panembahan Senopati (terbuat dari sehelai kain yang pernah dikenakan Nabi Muhammad). Ada pula pusaka berupa karya seni, yaitu: wayang kulit, gamelan, dan tarian yang disakralkan, termasuk wayang wong. Selain itu, berupa kereta kuda, yaitu Nyai Jimat dan Kanjeng Kyahi Garudhayaksa. Sultan memberi nama dan gelar Kanjeng Kyahi Garudhayaksa (Yang Mulia Burung Garuda Raksasa), karena garuda adalah tunggangan Dewa Wisnu. Jadi, dengan penamaan tersebut Sultan telah mengidentifikasikan diri sebagai dewa.

Menurut Wasisto (1969: 3), benda pusaka yang berwujud gamelan ada yang telah berusia 300-500 tahun, yaitu peninggalan dari Kerajaan Demak dan Majapahit. Vetter (1985: 114) menjelaskan bahwa gamelan kraton adalah salah satu identitas penting yang dipercaya mempunyai kekuatan magis. Masyarakat percaya bahwa masing-masing perangkatnya dikuasai oleh makhluk halus. Kesakralannya berdampak pada penghormatan yang melebihi manusia biasa, misalnya dengan cara disembah. Selain itu juga diberi sesaji atau dimandikan melalui upacara ritual tertentu (Margana, 2010: 471). Pengertian pusaka bukan hanya sesuatu yang bersifat bendawi, tetapi juga yang bersifat nonbendawi, misalnya tarian sakral atau dramatari wayang wong. Heroisme dan patriotisme dalam kisah yang diceritakan sangat sesuai dengan karakter Sultan yang maskulin (Soedarsono, 2003: 102). Jadi, konsepsi kedudukan tersebut dipikirkan sebagai sarana untuk mewujudkan fungsinya sebagai penguasa atau pengatur dunia.

\section{Upacara Ritual dan Keagamaan}

Salah satu tugas raja di Jawa adalah melestarikan hubungan ritual dengan nenek moyangnya. Tujuannya adalah untuk menerima kekuatan magis yang baru agar dapat memperkuat kedudukannya. Contohnya digambarkan dalam mitologi hubungan raja Mataram Islam dengan Kanjeng Ratu Kidul (Ratu Pantai Selatan), seperti yang digambarkan dalam Bedhaya Ketawang. Mengingat taran sakral tersebut sudah menjadi pusaka milik Kraton Surakarta, maka Sultan mengganti dengan upacara labuhan (Soedarsono, 1997: 361). Sultan tetap menjaga dan memperkuat keabsahan kedudukannya sebagai raja melalui cara tersebut. Selain itu, dilakukan pula melalui upacara ritual keagamaan, misalnya: peringatan hari lahir Nabi Muhammad pada tanggal 12 Rabiullawal/Maulid/Mulud. Rangkaian acaranya diakhiri dengan upacara Garebeg Mulud. Ada dua ritual garebeg lainnya, yaitu: Garebeg Sawal dan Besar (Soelarto, tt.: 41-42). Melalui upacara ritual dan budaya tersebut, berarti Sultan telah melaksanakan fungsinya sebagai abdi Tuhan, pimpinan atau pengatur agama, dan pengganti Nabi Muhammad (Soelarto, tt.: 24). Pergelaran wayang wong juga mempunyai tujuan terkait konsepsi kekuasaan. Ribuan rakyat yang datang selalu berharap untuk mendapatkan berkah dari kekuatan magis Sultan (Brandon, 2003, 171). Upacara ritual terkait lainnya adalah penobatan, ulang tahun, dan perkawinan putra/putri raja yang diselenggarakan secara mewah. Adapun tujuan yang ingin dicapai adalah untuk menunjukkan kebesaran dan kemakmuran raja (Soedarsono, 1997, 175-177).

\section{Angka dan Bangunan Sakral}

Kebudayaan yang dilestarikan kraton merupakan alam pikiran dan tradisi yang berpijak pada kepercayaan lama (Soelarto, tt.: 37). Pemilihan tempat dan pemberian nama kraton juga diperhitungkan dengan cara dan pemikiran yang sama (Purwadi, 2007: 474). Segala sesuatunya dipikirkan agar memiliki nilai sakral, termasuk kepercayaan terhadap angka sembilan yang dikaitkan dengan jumlah penjaga mata angin pada budaya Hindu, penari 
raket (jaman Majapahit), penari bedhaya, wali penyebar agama Islam di Jawa atau pintu gerbang Kraton Yogyakarta. Sama halnya dengan angka lima, seperti jumlah pintu gerbang yang menghubungkan kraton dengan dunia luar. Demikian pula dengan pembagian wilayah kraton yang disebut negara agung. Wilayah di luar kraton dibagi menjadi lima bagian (Kedu, Bumi Gedhe, Bagelen, Pajang) dan kuthagara sebagai pusatnya. Konsepsi tersebut mungkin dikaitkan dengan kosmologi Jawa, yaitu: sedulur keblat papat lima pancer. (Soedarsono, 1997: 123-126).

\section{Stratifikasi Sosial dan Bahasa}

Konsepsi kedudukan raja juga membedakan status sosial menjadi tiga golongan, yaitu: bangsawan, priyayi dan rakyat. Stratifikasi juga ditunjukkan melalui bahasa yang dipergunakan. Bahasa pengantar lokal kraton disebut basa kedhaton atau basa bagongan (Soelarto, tt.: 31-35). Selain itu, masih ada tingkatan (undha-usuk) yang dibagi dalam 3 sub, yaitu: ngoko, madya, dan krama. Masing-masing masih dibagi lagi menjadi 9 sub-sub tingkatan, yaitu: ngoko lugu, antya basa, basa antya, madya ngoko, madyantara, madya krama, wredha krama, kramantara, dan mudha krama (Soedarsono, 1997: 277). Banyaknya tingkatan bahasa semakin menjauhkan jarak antara raja dengan rakyat biasa (Soedarsono, 2003: 106). Dengan demikian, ada batas-batas tertentu yang memberikan perbedaan lapisan masyarakat. Jadi, konsepsi kedudukan raja dapat dibangun melalui aspek di atas untuk memperkokoh kebesaran, kewibawaan, dan kekuasaan raja.

\section{Kepribadian Sri Sultan HB I}

\section{Sikap}

Yasadipura I dalam Serat Babad Giyanti menjelaskan, bahwa Sri Sultan HB I digambarkan sebagai ksatria agung, berwajah tampan, berpikiran cerdas, pandai berbicara dan sangat cekatan (Djoko Dwiyanto \& Purwadi, 2002: 34). Ia juga menjunjung tinggi nilai kejujuran, gigih dalam menggapai tujuan mulia dan mampu membentuk kepribadian yang baik
(Purwadi, 2006: 472). Kepribadian Sultan sangat sesuai dengan sikap Panembahan Senopati, seperti yang digambarkan pada tembang macapat Sinom dalam Serat Wedhatama gubahan Sri Mangkunegara IV.

\section{Nulada laku utama}

Tumrape wong tanah Jawi

Wong agung ing Ngeksiganda

Panembahan Senopati

Kapati amarsudi

Sudane hawa lan nepsu

Pinesu tapa brata

Tanapi ing siyang ratri

Amemangun karyenak tyasing sasama.

Ambawani Tanah Jawa,

Kang padha jumeneng aji,

Satriya dibya sumbaga,

Tan lyan trahing Senopati,

Pan iku pantes ugi,

Tinulad labetipun,

Ing sakuwasanira,

Enake jaman mangkin,

Sayektine tan bisa ngepleki kuna

(Adityo Jatmiko, 2005, 23-24).

(Tauladanilah perilaku [yang] baik

Bagi orang Jawa

Bangsawan di Ngeksiganda

Panembahan Senopati

Selalu berupaya/mempelajari

Mengurangi hawa nafsu

Suka sekali bertapa

Juga diwaktu siang [atau] malam

Membangun kesenangan hati [perasaan] sesama.

Menguasai pulau Jawa,

Semua yang berkedudukan sebagai raja,

Ksatria yang mempunyai kelebihan dan terkenal,

Tidak lain adalah keturunan Senopati,

Yang itu pantas juga,

Dicontoh perjuangannya,

Dalam upayanya,

Memakmurkan masa depan,

Bisa jadi tidak sama dengan [keadaan] jaman dahulu) 
Gubernur Hartingh, dalam sebuah surat tertanggal 26 Oktober 1761 menerangkan sikap Sultan kepada van Ossenberg (penggantinya). Menurut Hartingh, Sultan adalah sosok yang sopan, matang dalam berpikir, mampu mengelola perasaan batin, berpendirian teguh, berpenampilan dan bergaya hidup sederhana, kreatif, dan menjunjung tinggi hak dan kehormatan (Purwadi, 2006).

\section{Heroisme dan Patriotisme}

Pertikaian yang terjadi pada Kerajaan Mataram terutama dilatarbelakangi perebutan kekuasan yang berkembang menjadi konflik keluarga kerajaan. Penyebab lainnya ditimbulkan dari intervensi Belanda melalui VOC. Krisis politik dan ekonomi berkembang meluas, sehingga raja beserta pejabat istana kehilangan kewibawaannya (Adityo Jatmiko, 2005: 100). Permasalahannya selalu dimulai dari tidak berhasilnnya suksesi dan kekosongan tahta di kerajaan Mataram. Kasus tersebut terjadi setelah berakhirnya masa kekuasaan Sunan Amangkurat II (1703) dan Sunan Paku Buwono I (1719) karena wafat.

Demikian juga dengan Sunan Amangkurat IV (1727) yang meninggalkan permasalahan, yaitu pertikaian antar keluarga kerajaan. Belum lama penggantinya menduduki tahta, terjadi perebutan kekuasaan (30 Juni 1742). Pemberontakan tersebut dipimpin oleh Mas Garendi (Sunan Kuning), cucu Sunan Mas yang bekerjasama dengan pasukan Cina (Adityo Jatmiko, 2005: 259). Pergolakan tersebut mengakibatkan Kerajaan Mataram harus kehilangan wilayah Rembang, Pasuruan, Surabaya, dan pulau Madura sebagai balas jasa kepada VOC (Adityo Jatmiko, 2005: 4).

Peperangan tersebut telah mengakibatkan kondisi kraton menjadi rusak parah, sehingga Sunan Paku Buwono II memindahkan ibukota kerajaan Mataram ke desa Sala, Surakarta dan mengganti namanya menjadi Surakarta Adiningrat. Selang beberapa waktu kemudian, Pangeran Mangkubumi meninggalkan Kraton Surakarta. Alasannya, Sunan Paku Buwono II telah menyerahkan seluruh wilayah pulau
Madura dan pesisir utara Jawa kepada VOC. Ini mendorong kemauan Pangeran Mangkubumi untuk melakukan perlawanan dari luar kraton. Akibatnya, dari penyerahan kekuasaan tersebut, nama dan kejayaan kerajaan Mataram yang telah dibangun dan ditegakkan oleh Sultan Agung (1613-1646) menjadi pudar. Wilayahnya mengecil dan menyebabkan berkurangnya sumber keuangan negara (Soedarsono, 1997: 94-95).

Kekuasaan raja tidak lebih dari seorang leenman atau 'peminjam kekuasan' dari Belanda (Adityo Jatmiko, 2005: 4-5). Akhir masa kekuasaan Paku Buwono II terjadi krisis kekosongan tahta di Kerajaan Mataram, sehingga situasinya menjadi kacau. Sunan Paku Buwono II merasa belum mendapatkan pengganti yang tepat dan ditambah lagi dengan keinginannya untuk hidup sebagai pendeta. Pangeran Mangkubumi mendapat dukungan pengikutnya untuk bertahta sebagai raja. Penobatannya dilakukan pada 11 Desember 1749 di desa Kebanaran. Oleh sebab itu, Mangkubumi juga dikenal dengan sebutan Susuhunan Kebanaran. Hutang kepada VOC semakin banyak, hingga pada suatu saat Sunan Paku Buwono II dipaksa menandatangani perjanjian dengan VOC untuk menyerahkan Mataram. Pangeran Mangkubumi merasa terusik dan melakukan perlawanan. Menurut pendapatnya, kekuasaan dan kedaulatan kerajaan Mataram telah dijual kepada VOC. Peristiwa tersebut semakin menimbulkan sikap heroik dan patriotik (Djoko Dwiyanto \& Purwadi, 2002: 12-17). Pertikaian di dalam keluarga kerajaan terus berlanjut dan mengakibatkan stabilitas ekonomi-politik semakin kacau, sehingga Mataram menjadi bangkrut (Vetter, 2001: 42). Peristiwa tersebut semakin mendewasakan Pangeran Mangkubumi dalam berpikir dan bersikap.

Selanjutnya, dalam situasi yang masih kacau tersebut, VOC menobatkan Paku Buwono III. Namun, Pangeran Mangkubumi tidak setuju dengan sikapnya yang terlalu lemah terhadap VOC. Akhirnya, perjuangannya membuahkan hasil setelah melakukan perlawanan selama 6 tahun (1749-1755). VOC 
mengundang Mangkubumi untuk berunding dengan Sunan Paku Buwono III. Peristiwa tersebut dikenal dengan Perjanjian Giyanti yang membagi Mataram menjadi dua (Adityo Jatmiko, 2005: 262). Mangkubumi tetap menentang Belanda dan mewariskan sikap tersebut kepada keturunannya. Sementara, Kraton Surakarta seolah menerima tradisi orang Belanda, namun sebetulnya tidak demikian kenyataannya. Terbukti dengan perlawanan Sunan Paku Buwono XII dan Sri Sultan HB IX kepada Belanda pada masa revolusi (19451949) (Sutton, 1991: 20).

Uraian tersebut membuktikan bahwa Mangkubumi adalah sosok 'Pahlawan Besar', sangat bijaksana dan tepat dijadikan sebagai pemimpin. Sama sekali tidak benar, bila disebut sebagai pemberontak. Keteguhan hati dan keberaniannya mendorong perjuangan untuk mencapai keinginan yang luhur. Semangat kepahlawanan dan keberaniannya sangat sesuai dengan nilai-nilai keprajuritan. Berpijak pada uraian tersebut pula dapat dimengerti, bahwa di balik statusnya sebagai bangsawanan terdapat kepribadian yang kuat, berani menentang kebijakan yang salah, memerangi kesewenangwenangan, dan melawan kekuatan militer VOC. Selain itu, ia dapat bertindak tegas, bijaksana, terbuka, dan berterus-terang dalam berbicara atau mengemukakan pendapat yang mencerminkan sikap heroik dan patriotik.

\section{Maskulinitas}

Pangeran Mangkubumi digambarkan sebagai sebuah pribadi yang cekatan, trampil, cerdas, cakap, gagah, tampan, dan berwibawa. Berpijak pada pernyataan tersebut, ada tiga hal yang mencerminkan adanya kepribadian maskulin, yaitu: gagah, tampan, dan berwibawa. Menuurut makna leksikal, kata 'gagah' mempunyai pengertian kuat, bertenaga, pemberani, atau besar dan tegap serta kuat (untuk badan). 'Tampan' berarti elok, gagah, cocok/patut untuk roman muka, air muka, rupa, atau sikap. Dapat diartikan juga sebagai sikap atau bentuk tubuh yang bagus. Berwibawa adalah pembawaan untuk mempengaruhi orang lain melalui sikap dan tingkah laku yang mengandung kepemimpinan dan penuh daya tarik (Periksa Suharso dan Ana Retnoningsih, 2012). Jadi, pengertian dari ketiganya mengandung unsur yang mengarah pada sifat kelakilakian atau maskulin.

\section{Pengaruh Kepribadian Sultan HB I}

Sultan mencurahkan segenap tenaga, pikiran, dan daya kreativitas untuk menciptakan sesuatu yang baru terkait suasana, kehidupan, aliran, dan corak ragamnya. Ada dua hal yang perlu untuk diperhatikan, yaitu upaya mendirikan kraton sebagai pusat kegiatan dan membentuk karakter pemerintahan yang berbeda. Pahit getir pengalaman hidup telah mendewasakan pola berpikir Sri Sultan HB I dan membentuk kepribadiannya sebagai sosok yang berbudi pekerti luhur, tegas, berpendirian teguh, dan berwibawa. Mengingat bahwa Kerajaan Mataram pernah menderita akibat diombang-ambingkan oleh pihak asing (Vetter, 1985, 41), Sultan menyatakan perlu untuk membangun karakter pemerintahan kerajaan yang mandiri, tegas, bermartabat, berwibawa, dan berbudaya luhur.

Kraton Yogyakarta pada awal masa perkembangannya masih dalam keadaan yang sulit (Vetter, 1985: 288). Banyak biaya yang harus dikeluarkan untuk pengadaan kebutuhan di segala sektor (Ong Hok Ham, 2002: 35). Oleh sebab itu, kehidupan kebudayaan atau keseniannya belum mendapatkan perhatian yang cukup. Namun, Sri Sultan HB I adalah sosok yang dikenal masyarakat sebagai 'seorang seniman besar' (Soedarsono, 1997: 141). Kondisi tersebut tidak menyurutkan semangatnya untuk menciptakan karya seni sebagai ciri khas Kraton Yogyakarta, salah satunya adalah karawitan. Situasi negara yang belum kondusif memaksa Sultan meluangkan sebagian besar waktunya untuk mengatasi permasalahan keamanan. Kondisi perekonomian yang belum stabil menjadi kendala pada perkembangan karawitan.

Semula, koleksi gamelan Yogyakarta hanya terdiri dari tiga perangkat saja. Ketiganya diperoleh melalui pembagian pusaka pada Perjanjian Giyanti (Vetter, 1986: 130). Adapun jenis, nama, dan gelar gamelan tersebut adalah, gamelan Munggang 
(Kanjeng Kyahi Gunturlaut), gamelan KodhokNgorèk (Kanjeng Kyahi Kebo-ganggang atau Maesaganggang) dan gamelan Sekati (Kanjeng Kyahi Gunturmadu) (Soedarsono, 2003: 139-141). Ketiganya berupa gamelan pakurmatan yang mempunyai keterbatasan pada jenis ricikan, jumlah ricikan, jumlah nada, dan fungsi dalam instrumentasinya. Selanjutnya, dengan segala keterbatasan tersebut, bagaimana gagasan pengembangan musikal atau non-musikal yang dilakukan Sri Sultan HB I pada seni karawitan pada saat itu? Mengapa diperlukan adanya upaya untuk melakukan pengembangan pada seni karawitan? Bagaimana langkah yang ditempuh Sultan untuk mewujudkannya? Berikut ini adalah penjelasan selengkapnya.

Kenyataan yang baru menunjukkan bahwa terkait dengan perkembangan teknologi, penggarapan rekaman musik pop saat ini telah melibatkan berbagai pemain musik dari pemain sitar atau shakuhachi hingga pemain orkestra. Hal ini menunjukkan bahwa pada taraf ini musik populer telah menuntut aktivitas kreatif yang meliputi berbagai kategori baik penggarapan komposisinya maupun dalam penggunaan dan perpaduan instrumennya yang lebih besar dibandingkan dengan sebelumnya.

\section{Pengembangan Musikal}

\section{Garap Gending}

Salah satu gagasan kreatif untuk memperkaya lagu dan menghidupkan rasa musikal dilakukan pada gamelan pusaka Kodhok Ngorèk. Sultan memerintahkan untuk memasukkan ricikan demung dan dua buah saron ricik pada repertoar Gending Kodhok Ngorek Ayam Sepènan (Ayam Supenang) (Soedarsono, 1997: 140-141). Gending Kodhok Ngorek pada gaya Yogyakarta maupun Surakarta dimainkan dengan pola garap irama yang sama. Berawal dengan irama yang seseg (cepat), kemudian berubah menjadi irama tamban (pelan), dan kembali lagi pada irama seseg (Supanggah, 2002: 36). Gagasan pengembangannya dilakukan saat memasuki irama tamban. Ketiga ricikan tambahan memainkan perannya dengan memainkan lagu di berikut ini.
Bagian a) di bawah ini merupakan lagu utama yang dimainkan pada ricikan pencon dengan pola ketukan ngracik pada irama I (seseg), sedangkan bagian b) dimainkan pada irama II (tamban).

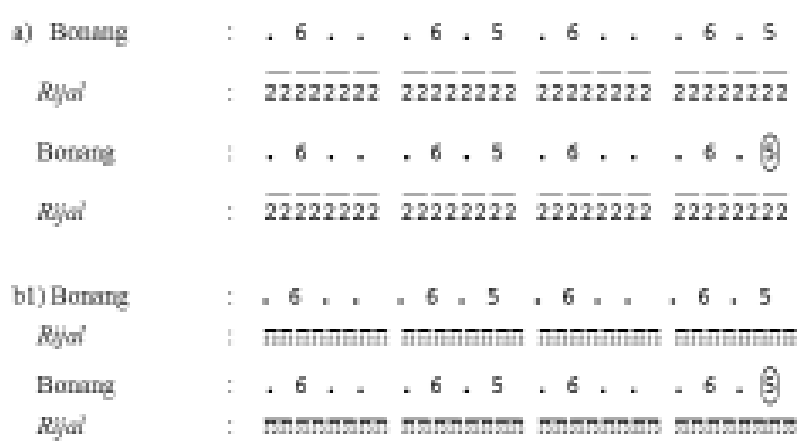

Bagian b2) di bawah ini dimainkan di atas lapisan lagu utama (notasi di atas) pada ketukan ngracik. sesudah memasuki irama II (irama tanggung).

b2) Denuyusanav = - 352356563252356 .56356 i 6 i 56 i 653 (

Supanggah (2002: 34) menjelaskan, Kodhok Ngorek di Surakarta berfungsi sebagai tanda memberi tahu atau pengumuman, misalnya kelahiran atau kematian keluarga raja (berjenis kelamin perempuan). Oleh sebab itu, diasosiasikan feminin, seperti nuansanya yang relatif halus. Sebaliknya, Sultan mengubah rasa gendingnya menjadi agung, gagah, $m r a b u$, ngratoni, berkesan tegas dan mantap.

\section{Garap Penyajian}

Gagasan pengembangan musikal kedua, dilakukan Sultan pada penyajian karawitan yang disebut nguyu-uyu. Caranya dengan menerapkan caking (baca: cak-ing) atau cak-cakaning (baca: cak-cak-aning) karawitan yang disebut 'soran' (Purwadi, 2006: 308). Caranya adalah dengan menciptakan sajian instrumentalia yang ditabuh secara keras (sora). Idiom karawitan pada saat itu menyebutnya dengan istilah 'uyon-uyon soran'. Bunyi yang dihasilkan dari cara tersebut menimbulkan rasa musikal yang bersemangat, bernuansa agung, gagah, berwibawa, mrabu, dan ngratoni. Jadi, Sri Sultan HB I telah mengekspresikan rasa musikal dan kreativitasnya sesuai dengan sifat maskulin, heroik dan patriotik. 


\section{Kreativitas Pengolahan Bunyi}

Pengembangan musikalitas pada uyunuyon soran didukung dengan penciptaan larasan 'umyung' atau riuh pada gamelannya. Sangat cocok sekali untuk menyajikan gending soran. Nuansanya riuh, gemuruh, dan menggelora, sehingga menumbuhkan sifat kelaki-lakian, gagah berani, dahsyat, kuat, tampan dan perkasa. Larasan umyung justru terasa janggal apabila dimainkan lirih, karena menghasilkan gelombang bunyi yang sangat jelas. Metode pemyetemannya dilakukan dengan memanjangpendekkan jarak nada (Purwadi, 2006: 308). Gamelan kraton yang dilaras dengan sedikit perbedaan nada pada masingmasing pasangan atau kelompoknya adalah Kanjeng Kyahi Guntursari (Sutton, 1991: 27).

\section{Pengembangan Non-Musikal}

\section{Pembuatan Gamelan}

Sultan memerintahkan abdi dalem untuk menciptakan satu pangkon gamelan berlaras pelog (Sorrell, 2000: 45). Proses pembuatannya dilakukan dengan cara 'mutrani' atau mengimitasi Kanjeng Kyahi Gunturmadu. Gamelan baru tersebut diberi nama dan gelar 'Kanjeng Kyahi Guntursari' (Yang Mulia Guntur Yang Indah (Soedarsono, 1997: 152). Semula, fungsi utamanya adalah untuk mengiringi beksan Trunajaya atau Beksan Lawung. Tujuannya agar dapat mengimbangi karakter tarian yang sangat gagah (Purwadi, 2006: 334). Kesan anggun, gagah, dan agung pada beksan yang dimaksud dapat terwujud, salah satunya karena material sumber bunyinya lebih besar dan tebal. Selain itu, jumlah ricikan pada demung, saron, dan peking adalah dua kali lipat dari biasanya (Soedarsono, 2003, 120-121).

\section{Penciptaan Gaya}

Pangeran Mangkubumi bertahta di kerajaan yang didirikan di sekitar bekas kerajaan Mataram Islam. Pemilihan wilayahnya menguatkan Kraton Yogyakarta lebih populer disebut Mataram. Tuntutan pengakuan sebagai penguasa Mataram yang syah, mendapat hak untuk mewarisi dan melanjutkan budaya Mataram (Waridi, 2006: 128). Artinya, pembagian negara saat itu juga diikuti dengan pembelahan budaya (Sutton, 1991: 19-22). Keputusan Sultan untuk melanjutkan budaya Mataram sangat beralasan. Kebesaran dan kewibawaan nama kerajaan tersebut telah dibangun atas dasar heroisme dan patriotisme Panembahan Senopati. Demikian juga dengan Sultan Agung Hanyakrakusuma yang berani melawan Kompeni hingga ke Batavia (Ricklefs, 1995: 67). Rupanya kedua sifat tersebut juga diwarisi oleh Sri Sultan HB I. Kebesaran dan kewibawaan kerajaan Mataram Islam diwujudkan kembali di Kraton Yogyakarta.

Semula, istilah Mentaraman atau Mataraman, salah satunya dipergunakan untuk menyebutkan tradisi karawitan gaya Yogyakarta (Sutton, 1991: 7). Keduanya menjadi ciri khas budaya yang bersumber dari kraton Yogyakarta. Sesuai perkembangannya dipergunakan untuk menyebutkan budaya dari luar tembok kraton, misalnya: dagelan Mataram, ketoprak Mataram, bahkan grup acapella yang sedang berkembang pada saat ini juga dinamai 'Acapella Mataraman'. Alasan penamaannya didasari adanya keinginan penggagasnya untuk menunjukkan identitas, bahwa kelompok tersebut berasal dari wilayah Yogyakarta.

\section{Penutup}

Berpijak pada semua uraian di depan dapat diketahui bahwa upaya Sultan untuk memperkokoh kebesaran, kekuasaan, dan kewibawaannya dilakukan dengan merancang konsepsi kedudukan raja. Gagasan tersebut diterapkan pada kelima aspek yang telah diuraikan. Selain itu, yang tidak kalah pentingnya adalah kepribadian Sultan yang sangat berpengaruh pada perkembangan dan karakter 'seni istana' Kraton Yogyakarta. Salah satunya telah diwujudkan dalam seni karawitan. Gagasan pengembangan musikal dan non-musikal merupakan pemikiran kreatif yang berpijak pada kepribadiannya. Upaya tersebut menghasilkan nuansa musik yang berkarakter agung, gagah, tampan, tegas, mantap, berwibawa, mrabu 
dan ngratoni. Langkah yang telah dilakukan Sultan membuktikan kebesaran, kekuasaan, dan kewibawaan Kraton Yogyakarta yang dibentuk dengan pijakan pada kepribadiannya.

\section{Kepustakaan}

Brandon, James R. 2003. Theater in Southeast Asia. Diterjemahkan oleh Soedarsono. Jejak-Jejak Seni Pertunjukan Asia Tenggara. Bandung: P4ST UPI.

Damami, Mohammad. 2002. Kanjeng Kyahi Suryaraja: Kitab Pusaka Kraton Ngayogyakarta Hadiningrat. Yogyakarta: Yayasan Kebudayaan Islam Indonesia bekerjasama dengan IAIN Sunan Kalijaga Yogyakarta.

Dwiyanto, Djoko \& Purwadi. 2002. Perjuangan Kraton Yogyakarta, Jasa Sri Sultan HB I-X. Yogyakarta: Pustaka Raja.

Ham, Ong Hok. 2002. Dari Soal Priyayi Sampai Nyi Blorong: Refleksi Historis Nusantara. Jakarta: Penerbit Buku Kompas.

Jatmiko, Adityo. 2005. Tafsir Ajaran Serat Wedatama. Yogyakarta: Pura Pustaka.

Margana, S. 2010. Kraton Surakarta dan Yogyakarta 1769-1874. Yogyakarta: Pustaka Pelajar.

Moedjanto. 2007. Konsep Kekuasaan Jawa, Penerapannya oleh Raja-Raja Mataram. Yogyakarta: Kanisius.

Mudjanattistomo. 1977. Pedhalangan Ngayogyakarta Jilid I (Yogyakarta: Yayasan Habirandha.

Nurhayati, Endang. 2006. Filsafat dan Ajaran Hi-dup: Dalam Khasanah Budaya Keraton Yogyakarta. Yogyakarta: YKII-UIN Sunan Kalijaga.

Poerwadarminta, W. J. S. 1937. Baoesastra Djawa. Batavia: J. B. Wolters-Groningen.

Purwadi. 2006. Sejarah Kanjeng Sultan Hamengku Buwono IX. Yogyakarta: Hanan Pustaka. 2007. Sistem Pemerintahan Kerajaan
Jawa Klasik. Medan: Penerbit Pujakesuma. Ricklefs, MC. 1995. Sejarah Indonesia Modern. Terjemahan Dharmono Hardjo-widjono. Yogyakarta: Gadjah Mada University Press. Soedarsono. 2002. Seni Pertunjukan Indonesia di Era Globalisasi, Edisi Ketiga Yang Diperluas. Yogyakarta: Gadjah Mada University. 2003. Seni Pertunjukan Dari Perspektif

Politik, Sosial, dan Ekonomi. Yogyakarta:

Gadjah Mada University Press. 1997. Wayang Wong, Dramatari Ritual

Kenegaraan di Keraton Yogyakarta. Yogyakarta: Gadjah Mada University Press.

Soelarto, B. tt. Garebeg di Kasultanan Yogyakarta. Sorrell, Neil. 2000. A Guide to the Gamelan. Ithaca: Society for Asian Music.

Sumarsam. 2002. Hayatan Gamelan, Kedalaman Lagu, Teori \& Perspektif. Surakarta: ISI Press. Supanggah, Rahayu. 2002. Bothekan Karawitan

I. Jakarta: Masyarakat Seni Pertunjukan Indonesia.

Surjodiningrat, Wasisto. 1969. Penyelidikan Dalam Pengukuran Nada Gamelan-Gamelan Jawa Terkemuka Di Yogyakarta dan Surakarta. Yogyakarta: Laboratorium Akustik Bagian Mesin-Fakultas Teknik UGM.

Suseno, SJ. Franz-Magnis. 1985. Etika Jawa, Sebuah Analisa Falsafi tentang Kebijakan Hidup Jawa. Jakarta: PT. Gramedia.

Sutton, R. Anderson. 1991. Traditions of GamelanMusic in Java: Musical Pluralism and Regional Identity. Cambridge: Cambridge University Press.

Vetter, Roger R. 1986. "Music For The Lap of The Worlds: Gamelan Performance, Performers, and Repertoire in The Kraton Yogyakarta" [Disertasi] University of Wisconsin-Madison. Waridi. 2006. Karawitan Jawa Masa Pemerintahan PB X: PerspektifHistoris dan Teoretis. Surakarta: ISI Press. 